\title{
La política exterior de los gobiernos Kirchner (2003-2009)
}

Felipe de la Balze*

La Argentina realizó un firme vuelco en su política exterior durante las primeras presidencias del ciclo democrático que se inició en 1983 (Alfonsín, Menem, de la Rúa). Se aproximó a Brasil, Chile y Estados Unidos, países que en el pasado había considerado como competidores y, en circunstancias puntuales, como potenciales adversarios. Además restableció la relación con Europa, dañada por las consecuencias de la guerra de las Malvinas y atrajo un enorme flujo de inversiones directas del Viejo Continente.

Los principales pilares de dicha política fueron la creación del Mercosur y el fin de la competencia militar (inclusive nuclear) con Brasil; la solución de los centenarios desacuerdos limítrofes con Chile y avances sustantivos en la integración bilateral; el logro de una relación cooperativa y amistosa con los Estados Unidos; la profundización de la relación económica y política con las principales naciones europeas y una mayor inserción en el comercio mundial ${ }^{1}$.

El severo deterioro en los términos de intercambio de nuestro comercio exterior (a partir de 1997), la sorpresiva maxi devaluación del Real brasilero en 1999 y un creciente endeudamiento del sector público debilitaron la posición externa del país y socavaron los fundamentos del régimen de la convertibilidad ( 1 peso = 1 dólar), creado en 1991.

El atraso en el tipo de cambio, que se hizo notorio a partir de 1998, encareció los salarios en dólares, redujo la competitividad de las empresas locales, incrementó la tasa de desempleo y redujo la rentabilidad de numerosas pequeñas

Economista y negociador internacional. de la Balze, Felipe A.M. (1997), La Política Exterior en Tres Tiempos, en: Argentina y EE.UU., Fundamentos de una Nueva Alianza, Felipe A.M. de la Balze (comp.), Buenos Aires, CARI. 
y medianas empresas, empleadoras de mano de obra.

La dirigencia argentina no pudo, o no supo, salir a tiempo y ordenadamente de la convertibilidad. La profunda depresión (el PBI per cápita cayó un $24 \%$ entre 1999 y 2003) y el virtual quiebre del sector bancario generaron una crisis sin precedentes en la historia del país.

La moratoria (el «default») sobre la deuda externa (diciembre año 2001) y la conversión de todos los contratos en dólares a pesos (la pesificación) produjeron fuertes pérdidas entre los inversores extranjeros que habían participado de la bonanza de los años anteriores.

Los argentinos también sufrieron masivas pérdidas. Casi el $60 \%$ de la deuda externa pública corresponden a instituciones e inversores argentinos y aproximadamente el $80 \%$ de los depósitos bancarios en dólares (pesificados) estaban en manos de pequeños y medianos ahorristas locales ${ }^{2}$.

Mientras que los bonistas extranjeros tardaron algún tiempo en organizar sus reclamos, las empresas extranjeras inversoras en los servicios públicos y en el sector energético ejercieron rápidamente presiones (inclusive a través de sus gobiernos) para proteger sus derechos. La mayoría de ellas terminaron presentando demandas de resarcimiento ante el Centro Internacional de Arreglo de Diferencias Relativas a las

2 Los empresarios locales también sufrieron las consecuencias del congelamiento de las tarifas y los controles de precios.
Inversiones (CIADI), organismo multilateral de arbitraje en la esfera del Banco Mundial, en el marco de los derechos que les otorgaban los acuerdos bilaterales de inversión que la Argentina había firmado con numerosos países desde fines de la década de 1980.

La moratoria incluyó fundamentalmente a los tenedores de bonos y a las Agencias de Crédito a la Exportación. La deuda con los organismos multilaterales (FMI, Banco Mundial y BID) fueron pagadas en tiempo y forma. El crédito comercial de corto plazo, que sufrió retrasos durante el año 2002, se regularizó a fines del 2003.

La moratoria, el rompimiento de los contratos que fijaban en dólares las tarifas de los servicios públicos y los controles sobre los precios de la energía (instrumentados a través de retenciones a la exportación) forjaron una larga lista de conflictos irresueltos con inversores extranjeros, que fueron heredados por la administración de Néstor Kirchner.

\section{LA POLÍTICA EXTERIOR (2003-2009)}

El 25 de mayo de 2003 Néstor Kirchner asumió como presidente. Con una baja legitimidad de origen (cosechó solo el $22 \%$ de los votos) y un país gravemente dañado por la crisis, Kirchner apuntó a ganar una alta legitimidad de ejercicio, mostrando un gobierno resuelto a reconstruir al país, en sus frentes interno y externo. 
Las consecuencias de la crisis de la política exterior del nuevo gobierno limitaron severamente los márgenes de maniobra. La gravedad de las circunstancias que vivió el país y la dificultad para encontrar explicaciones satisfactorias ante la población incentivaron la búsqueda de culpables.

El natural rencor que generaron en amplios segmentos de la población el desempleo, el congelamiento de los depósitos y las quiebras fue canalizado por el gobierno hacia un núcleo de chivos expiatorios: los «economistas neoliberales», el FMI, los banqueros «que se llevaron los depósitos» y las empresas extranjeras de servicios públicos.

Esta técnica de manipulación de la opinión pública tiene un neto sesgo autoritario y antidemocrático pues, al descalificar la legitimidad del oponente, imposibilita el debate con los que piensan diferente e inhibe el análisis objetivo y publico de lo ocurrido ${ }^{3}$.

La política exterior de los Kirchner también estuvo condicionada por sus orígenes políticos, en particular su afiliación ideológica a un peronismo de izquierda con rémoras aislacionistas e intervencionistas. La fragilidad política interna y la grave situación social (con recurrentes conflictos callejeros) han llevado en varias ocasiones a utilizar la

Vale la pena recordar, como antecedente, las reacciones de numerosos gobiernos europeos a las consecuencias de la Gran Depresión (década de 1930) que contribuyeron a generar xenofobia, persecuciones políticas y raciales, guerras y gobiernos totalitarios. política externa como variable de ajuste en un denodado esfuerzo por acumular capital político interno.

Su estilo ha estado marcado por su experiencia y trayectoria política previa en Santa Cruz, una provincia petrolera despoblada y remota, donde el ejercicio de poder depende fundamentalmente de una relación «mano a mano» con el poder central de Buenos Aires y con un puñado de empresas petroleras. Estas circunstancias marcaron un estilo negociador duro y poco afecto a la cortesía, que los Kirchner transmitieron a su política exterior (para sorpresa de las Cancillerías de otros países).

La primacía de la política interna sobre la externa dejó secuelas negativas en la posición internacional de nuestro país. A veces, por acción, como en el caso de la retórica anti-imperialista con los Estados Unidos: seguramente la diplomacia norteamericana no ha olvidado el escándalo internacional que ocurrió en la reunión de Mar del Plata (noviembre de 2005), cuando el presidente Néstor Kirchner trató duramente al presidente Bush delante de una treintena de presidentes en la reunión hemisferica en que se discutió el futuro del ALCA; otras veces, por inacción, cuando para congraciarse con actores políticos provinciales, el gobierno permitió que vecinos encrespados por potenciales riesgos ambientales bloquearan indefinidamente el principal puente internacional entre la Argentina y el Uruguay.

Finalmente, en otros casos, por temor, por ejemplo, cuando los su- 
ministros de gas natural boliviano comenzaron a escasear y el frío redujo los excedentes de gas local disponible. Un gobierno, aprensivo de las consecuencias políticas que tendrían los cortes domiciliarios, anunció intempestivamente recortes a las exportaciones de gas a Chile y suscitó un problema internacional que produjo conmoción en la opinión pública del país vecino.

La política exterior de los gobiernos Kirchner es difícil de encasillar. La variedad y complejidad de los temas que entraron y salieron de la agenda, la primacía de la Casa Rosada sobre la diplomacia profesional en la toma de decisiones y un estilo de conducción marcado por la experiencia política previa en la provincia de Santa Cruz dificultan la observación.

A continuación, presentamos un análisis de los principales temas de la politica internacional durante los años 2003-2009. Hemos concentrado nuestros comentarios en solo nueve temas: siete bilaterales, incluyendo los Estados Unidos, Europa, Brasil, Venezuela, Chile, Bolivia y Uruguay y dos sectoriales: las políticas de comercio internacional y las relaciones con los organismos financieros internacionales.

Las relaciones con otros países importantes para nuestro país, como México, Paraguay, Perú, Sudáfrica y Rusia así como otros temas, estrechamente relacionados entre sí, como la política de defensa, el conflicto de las Malvinas, las políticas respecto al Atlántico Sur y a la Antártica, no han sido incorporadas a este análisis, pero tampoco afectan las conclusiones generales de este trabajo.

A pesar de la retórica gubernamental, en muchos temas (quizás más por inercia que por diseño) los lineamientos esenciales de la política exterior del período anterior (1983-2001) se mantuvieron indemnes.

No fue así, desafortunadamente, en el manejo de las formas. Y es sabido que en el mundo de las relaciones internacionales las formas son generalmente tan importantes como el fondo.

Dejar al presidente de otro país esperando en un aeropuerto por horas, aceptar una invitación a comer de una casa real europea y no aparecer en el convite, maltratar en público a un dignatario extranjero, bloquear el tráfico aéreo con una nación amiga sin realizar previamente una consulta, invitar a un presidente africano al país y luego dejar de recibirlo ( por sus antecedentes en materia de derechos humanos), fueron motivo de escándalo, generaron desconfianza y menoscabaron el prestigio internacional del país.

Infelizmente, en demasiadas ocasiones las urgencias políticas internas impusieron su primacía sobre cualquier otra consideración de largo plazo. En dichas circunstancias, la política exterior adquirió un sesgo aislacionista e introspectivo e incurrió en costos que el gobierno actual, o el que le suceda, a fines del 2011, deberá amortizar.

Además, a la política exterior de los Kirchner le costó interpretar y valorar las nuevas tendencias económicas y políticas internacionales y no supo 
aprovechar las oportunidades que ofrecía el escenario para mejorar el posicionamiento de nuestro país en el mundo. Otros países, principalmente asiáticos, pero también de nuestra región, como Brasil, Chile y Uruguay, se posicionaron mejor.

\section{Los Estados Unidos}

La relación durante los últimos siete años, con la primera potencia mundial, ha sido distante y formal ${ }^{4}$. Desafortunadamente, la Argentina no supo generar un clima de confianza con Washington que le permitiera avanzar sus intereses.

Sin embargo, a pesar de la ocasional retórica antinorteamericana, no hubo conflictos de fondo que empañaran la relación bilateral. En la práctica, en casi todos los temas la posición del gobierno fue coherente con el pasado. En la lucha contra el terrorismo, el combate al narcotráfico, los derechos humanos y la no proliferación de armas nucleares, los gobiernos Kirchner han trabajado en coordinación con el gobierno norteamericano.

Asimismo, junto con el gobierno norteamericano se mantuvo la presión sobre el gobierno de Irán (a través de INTERPOL e inclusive en los discursos presidenciales ante la Asamblea General de la Naciones Unidas) para que dicho país colabore en la resolución de los gravísimos atentados contra la

$4 \quad$ Discurso del presidente Néstor Kirchner ante el Congreso Nacional el 25 de mayo del año 2003, día en que asumió el mando. comunidad judía que ensangrentaron a la ciudad de Buenos Aires en la década anterior.

Inclusive en las Naciones Unidas, el voto argentino fue consistente con el de los gobiernos anteriores (con la excepción del tema de la condena respecto de los derechos humanos en Cuba).

La medida más confrontativa hacia los Estados Unidos fue el rechazo al proyecto norteamericano de crear una zona de libre comercio hemisférica (el ALCA) en la ya mencionada reunión de presidentes (Mar del Plata, noviembre de 2005).

Para medir el impacto de dicha reunión, sería bueno recordar que la decisión de no incorporarse al ALCA, salvo a través de una negociación conjunta de los cuatro países del Mercosur, fue tomada con anterioridad por los presidentes Menem y de la Rúa, en estrecha coordinación con Brasil.

Además, el rechazo al ALCA debe ser analizado en el contexto de las modificaciones que sufrió la política de los Estados Unidos hacia la región durante los últimos años. Después del atentado a las Torres Gemelas, la política comercial norteamericana perdió protagonismo a favor de las políticas de seguridad y defensa.

En la actualidad ${ }^{5}$, los Estados Unidos están prioritariamente interesados en su vecindario geográfico (México,

5 Ver: Report of the Partnership for the Americas Commission, the Brookings Institution, Washington D.C., November 2008 e Inter-American Dialogue, A Second Chance: U.S. Policy in the Americas. A 
el Caribe, Centro América, Colombia y Venezuela) y en la protección de sus inversiones en la región. En lo comercial, privilegian los acuerdos bilaterales (como los ahora vigentes con Centroamérica, el Caribe, Chile y Perú y los firmados, pero aún no ratificados, con Colombia y Panamá).

En los temas de seguridad hemisférica, priorizan aquellos directamente vinculados a su seguridad interna, en particular, el terrorismo islámico, el narcotráfico y la inmigración ilegal ${ }^{6}$.

El interés estratégico y militar por la Argentina y los países del Cono Sur es limitado, al no haber temas domésticos norteamericanos involucrados, ni conflictos importantes con sus empresas, ni amenazas externas o internas a la hegemonía norteamericana en el hemisferio ${ }^{7}$.

En líneas generales, la oposición de los Kirchner al liderazgo norteamericano es vista en los círculos dirigentes norteamericanos como más simbólica que real. No perciben verdaderos conflictos de interés (o de políticas) en la relación bilateral y creen que el gobierno argentino utiliza el antinorteamericanismo como un instrumento demagógico de política interna.

Report of the Sol Linowitz Forum, 2009, www.thedialogue.org.

6 United States Southern Command,» Command Strategy 2016. Partnership for the Americas», 2007, www.southcom.mil.

7 Tulchin Joseph, 2009, Challenges to the U.S. Security in the Hemisphere, Center for Hemispheric Policy, University of Miami.
El bajo perfil de la reacción norteamericana a las declaraciones airadas del gobierno argentino en relación con los comentarios realizados en Buenos Aires por el Secretario de Estado Adjunto (diciembre 2009) respecto de la preocupación (obvia) de algunas empresas norteamericanas sobre la seguridad jurídica en la Argentina, refuerzan esta interpretación.

Desde la asunción de Barak Obama al poder, el gobierno argentino se ha propuesto mejorar su acceso a la nueva Casa Blanca, con la intención de facilitar un entendimiento con el distante y vituperado Fondo Monetario Internacional, que abriría las puertas a un retorno del gobierno argentino al mercado financiero internacional.

Hasta ahora, el apoyo brindado por el gobierno norteamericano ha sido poco entusiasta. Como la confianza bilateral es escasa - ¿qué incentivos tendrían los Estados Unidos para modificar procedimientos no escritos, pero confirmados en la práctica habitual de los últimos cincuenta años- respecto del refinanciamiento de países altamente endeudados (exponiéndose a futuros pedidos de excepción por otros países), cuando la mayoría de las acreencias atrasadas de la Argentina son con las agencias de crédito a la exportación europeas y con tenedores de bonos europeos y de otros países?

\section{EUROPA}

Los países europeos tienen fuertes vínculos históricos, culturales y demográficos con nuestro país. Luego de 
un período de vigoroso acercamiento político y económico, la Argentina y Europa vivieron un penoso desencuentro. Sin duda, los intereses económicos europeos fueron los más perjudicados por las derivaciones de la crisis.

La diplomacia argentina ha realizado valiosos esfuerzos para restablecer un semblante de normalidad. Los desvelos para recomponer la relación fueron particularmente relevantes en los casos de Alemania, España, Italia y Francia, países con los cuales el nuestro ha tradicionalmente mantenido relaciones densas y amistosas. Sin embargo, la recomposición de la relación ha sido lenta y aún quedan temas conflictivos pendientes.

Las empresas europeas lideraron el proceso de privatización y modernización de los servicios públicos durante la década de 1990. La desordenada salida de la convertibilidad (en particular el congelamiento tarifario) creó un pasivo contingente grande, que se ha resuelto parcialmente, dejando heridos en el camino. Las empresas petroleras europeas cuestionaron las políticas instrumentadas por el gobierno para controlar la inflación- en particular, la imposición de retenciones móviles a la exportación de petróleo y el congelamiento de los precios del gas natural en boca de pozo.

Algunas empresas se retiraron disgustadas del país e iniciaron reclamos legales ante los tribunales internacionales, principalmente el CIADI. La mayoría decidió quedarse, negociar con el gobierno y simultáneamente iniciar reclamos legales ante los mismos tribunales.
A posteriori, el gobierno negoció con algunas empresas la extensión o la ampliación de la concesión y obtuvo el retiro de varios de los reclamos. Desafortunadamente, la lista de demandas en los tribunales es todavía extensa y el país podría perder varias de las controversias en disputa. Esperemos que el gobierno avance en las negociaciones pendientes para que los temas que herede la próxima administración no sean demasiado gravosos.

Por su parte, en el universo de las agencias de crédito a la exportación, las entidades europeas fueron las más afectadas por la moratoria argentina (son tenedoras de más del $65 \%$ de los créditos impagos). El gobierno argentino ha recurrentemente postergado la renegociación -en el llamado Club de París-al negarse a aceptar una revisión de la situación económica del país por el FMI ${ }^{8}$.

Desafortunadamente los precedentes no favorecen la postura argentina. El FMI ha sido el consejero permanente del Club de París desde su creación en 1956. La expectativa del gobierno argentino de modificar sus procedimientos habituales (aceptados por más de 40 países durante los últimos cincuenta años, inclusive el nuestro en varias ocasiones) es irrealista y ha generado desazón en varios gobiernos europeos.

8 Importantes proyectos de inversión del sector privado han sido postergados al no poder obtener el crédito de las agencias de exportación que financian, a largo plazo y a bajas tasas, la importación de bienes de inversión. 
Las agencias son instituciones de crédito gubernamentales o cuasi- gubernamentales y, después de un período prudencial de espera, los créditos impagos son transferidos a las tesorerías nacionales. Esto genera un problema bilateral cuando anualmente, en la ocasión del debate presupuestario, la situación de incumplimiento del deudor es traída a la palestra en los niveles más altos del Estado (incluso los parlamentos), donde los reproches argentinos al FMI caen en saco roto.

Finalmente, una porción de los tenedores de bonos (aproximadamente el $24 \%$ del total) no aceptaron la propuesta de canje de la deuda pública del año 2005. Entre ellos, había un segmento importante de pequeños y medianos inversores alemanes, italianos y japoneses. Este hecho es particularmente penoso, por las características de los inversores involucrados y por el impacto mediático -y en consecuencia político- que suscita esta circunstancia en el país de origen.

En la nueva propuesta de canje de deuda pública que el gobierno propone realizar durante los primeros meses del 2010 se incorporan, con buen tino, condiciones preferenciales para dicho universo de bonistas.

Los gobiernos Kirchner han intentado -sin demasiados resultados- fortalecer los lazos con algunos países europeos (entre ellos Alemania y Francia) a través de la concreción de grandes proyectos bilaterales.

El caso de Francia y el proyecto del «tren bala» es ilustrativo. Se trata de la puesta en marcha de un tren de alta velocidad entre las ciudades de Buenos Aires y Rosario. El equipamiento y la tecnología seria provista por un consorcio de empresas francesas paraestatales. El costo estimado del proyecto excedía los US\$ 5000 millones. La concreción del proyecto dependía del otorgamiento de garantías por parte del gobierno argentino y del financiamiento de la agencia de crédito a la exportación francesa.

La reacción de la opinión pública y de los expertos fue unánimemente crítica. El proyecto no es prioritario, su costo era altísimo y el hecho de que no hubiera una licitación pública internacional generó numerosas conjeturas.

Para restablecer una relación normal con Europa el gobierno necesita avanzar en la solución de los temas pendientes más urgentes para luego reconstruir, sobre bases más sólidas, la relación con el Viejo Continente.

Desde un punto de vista político, el tema de los bonistas individuales y la falta de voluntad de nuestro país para renegociar con el Club de París, son los que más dañan la reputación argentina. La plata involucrada no es mucha (se trata de refinanciar acreencias vencidas).

Los costos que el gobierno asume al no aceptar la participación consultiva del FMI en el proceso de renegociación son altos (restricciones de acceso al crédito europeo y un clima de hastío respecto a la Argentina en varios países europeos).

Sobrevuela el horizonte la posibilidad de volver a negociar un acuerdo 
de cooperación y libre comercio entre el Mercosur y la Unión Europea. El intento anterior fracasó en el año 2004 por diversas causas.

La oferta europea de liberalización en los temas agropecuarios era magra y pretendía trasladar la negociación de los temas más relevantes al ámbito multilateral de la Ronda Doha. La lista de conflictos bilaterales pendientes debilitaba la posición negociadora argentina. Finalmente, el previsible rechazo del Mercosur a la propuesta norteamericana del ALCA, creaban una situación diplomática delicada tanto para Itamaraty como para el Palacio San Martín.

La gradual resolución de algunos de los problemas pendientes y el deseo compartido de relanzar la negociación entre el Mercosur y la Unión Europea le ofrecen al gobierno argentino, una magnífica oportunidad, si saben aprovecharla, para normalizar la relación entre la Argentina y Europa.

\section{BRASIL}

Los gobiernos Kirchner priorizaron la consolidación de la relación estratégica con Brasil y la profundización del Mercosur. En los hechos, la relación con Brasil ha fluctuado entre una fructífera cooperación política y una sucesión de conflictos comerciales que han generado un cono de sombra sobre el futuro de la relación bilateral; en particular, si la oposición brasilera (donde las industrias paulistas están bien repre- sentadas) gana las próximas elecciones presidenciales?.

En el campo político, la cooperación bilateral es amplia, las consultas son permanentes y la coordinación en los diversos foros de negociación internacional es extensa, aun cuando las posiciones nacionales no siempre coincidan.

La divergencia política más sustantiva se refiere a las posiciones que cada país tomaría en el marco de una posible reforma del Consejo de Seguridad de las Naciones Unidas. Brasil se propone como miembro permanente del Consejo de Seguridad por mérito propio.

La administración Kirchner mantuvo la posición histórica argentina: el Consejo de Seguridad no debe ser un coto exclusivo de las grandes potencias y la representación de América del Sur debe ser compartida entre los países de la región -de acuerdo con una fórmula que refleje la importancia de cada uno de ellos y su participación en el ámbito de la defensa regional.

En el campo económico, la posición fue coherente con la de los gobiernos anteriores. La Argentina promueve la conveniencia de profundizar la integración económica bilateral, pero la condiciona a un fortalecimiento del marco institucional del Mercosur ${ }^{10}$.

9 Rubens Barbosa, «Ser o No Ser». Cronista Comercial, Buenos Aires, 4 de enero de 2010.

10 de la Balze, Felipe A.M. (2000), El destino del Mercosur: entre la Unión Aduanera y la Integración Imperfecta en: El Futuro del Mercosur: entre la Retórica y el Realismo, 
La Argentina critica las restricciones para-arancelarias que afectan el acceso de sus exportaciones al mercado brasileño, las subvenciones al financiamiento de las exportaciones y las políticas fiscales y de promoción de inversiones que, tanto al nivel federal como al nivel estatal, desequilibran el campo de juego.

Además, el arancel externo común del Mercosur crea una reserva de mercado para los sectores promocionados en Brasil (entre otros, electrodomésticos, maquinaria, material de transporte y auto-partes, celulares, calzado y vestuario) y beneficia con menores márgenes de preferencia a las exportaciones argentinas, que están más vinculadas al mercado mundial- con la excepción de los automóviles (donde rigen acuerdos de comercio administrado).

Ante la falta de respuesta brasileña a las demandas argentinas y en el marco de un fuerte superávit comercial que beneficia ampliamente al Brasil (aproximadamente US\$ 4000 millones durante el año 2008), la política comercial argentina se volvió más defensiva. Dicha circunstancia y la fuerte revaluación del Real (que reduce los márgenes de ganancia de los exportadores brasileños) han suscitando un incremento de los contenciosos comerciales bilaterales que se estima podrían estar afectando entre el $10 \%$ y el $15 \%$ del total del comercio bilateral).

de la Balze Felipe A.M., (comp.) Buenos Aires, CARI.
Para compensar en parte el malestar creciente en la relación comercial, el gobierno argentino anunció últimamente la compra de 20 aviones a Embraer, para fortalecer la flota de cabotaje de la recientemente estatizada Aerolíneas Argentinas.

La ausencia de un plan estratégico de mediano plazo respecto de Aerolíneas Argentinas, los problemas de incompatibilidad en la gestión de los repuestos (la flota actual es Airbus y Boeing) y la falta de una licitación pública, han suscitado desosiego tanto entre los expertos aeronáuticos como en la opinión publica informada.

Los beneficios políticos y estratégicos del Mercosur para la Argentina y para Brasil siguen siendo relevantes Pero en el campo económico, la integración está estancada. Una retórica vacua ( los reiterados anuncios de relanzamiento del Mercosur) y una extensa lista de conflictos comerciales, dominan la agenda bilateral.

Los gobiernos Kirchner y Lula, no han solucionado el impasse y se han transformado en meros gestores de una situación bilateral inestable y ambigua, a la que hasta ahora, no han sabido encontrarle una salida ${ }^{11}$.

${ }_{11}$ Diversas propuestas están en la palestra. Entre otras, ver de la Balze, Felipe A. M. Finding Allies in the Backyard. Foreign Affairs, August/September 2001. 
Felipe de la BAlze • La política exterior de los gobiernos Kirchner

\section{Venezuela}

La propuesta internacional más original, y a su vez la más problemática, de los gobiernos Kirchner, fue la de incorporar a Venezuela como miembro pleno del Mercosur. En principio, dicha incorporación fortalece la posición del Mercosur en las negociaciones internacionales. Venezuela es un jugador de primer rango en el escenario petrolero mundial. También es un importador de productos y servicios que los países del Mercosur pueden proveer competitivamente (la Argentina exportó US \$ 1800 millones durante el año 2008).

El problema es el régimen del presidente Chávez. Chávez fue democráticamente elegido pero ha consolidado su poder debilitando la independencia del poder judicial, persiguiendo a muchos de sus opositores y restringiendo la libertad de prensa.

$\mathrm{Su}$ agenda interna mezcla políticas sociales valiosas con medidas profundamente demagógicas. Su Revolución Bolivariana está erosionando el Estado de derecho y transformando a la democracia venezolana en un caso clásico de «tiranía de la mayoría».

La expropiación de Sidor (una empresa siderúrgica del grupo Techint) ha generado graves preocupaciones respecto de la seguridad jurídica de que gozarían las empresas privadas de la región, en un país cuyo gobierno se declara socialista a la vieja usanza.

Chávez ha intervenido en los asuntos internos de otros países de la región, aportando plata para sostener a gobiernos o partidos amigos, lo que ha suscitado desentendimientos con Chile, México y Perú. Su intromisión en los asuntos bolivianos debilita la tradicional presencia de la Argentina y de Brasil en dicho país y agrava los problemas de funcionamiento de la democracia boliviana.

Su decisión de designar a las FARC colombianas como «fuerzas insurgentes» ha suscitado un gravísimo conflicto con el gobierno colombiano del presidente Uribe que cataloga a las FARC como «movimiento narco-terrorista».

La relación entre los Estados Unidos y Venezuela en el campo económico ha sido eminentemente pragmática. Venezuela mantiene su posición de tercer proveedor mundial de petróleo a los Estados Unidos.Pero en el campo político y en el de la seguridad, la relación se ha vuelto particularmente agria durante los últimos tiempos y una larga letanía de presiones y contra presiones, empañan el clima bilateral y regional.

Hay una multitud de razones para pensar que la incorporación de una Venezuela chavista, poco propensa al respeto del Estado de derecho y a las reglas de la democracia representativa, no encaja con los objetivos declarados del Mercosur.

Para concretar una vinculación fructífera y de largo plazo, la Argentina y Brasil tendrían que convencer a Chávez de moderar su agenda interna y externa y de asumir compromisos serios en materia de integración comercial y de seguridad jurídica. Las probabilidades de éxito son muy bajas. 
Quizás habrá que esperar un cambio de régimen en Caracas para que la asociación entre Venezuela y el Mercosur tome vuelo.

\section{Chile}

La integración argentino-chilena avanzó velozmente durante las ultimas dos décadas, pero sufrió un mal trance cuando el gobierno argentino decidió recortar los envíos de gas natural a Chile durante el invierno del año 2004. Los gobiernos de ambos países han acordado medidas concretas que han contribuido a restablecer el vínculo. Pero la restauración de la confianza tomará su tiempo.

Entre 1983 y el 2001 los avances realizados en materia de delimitación de fronteras conflictivas e integración física y económica-incluyendo la construcción de gaseoductos que cruzaron la cordillera para proveer de gas natural a nuestro vecino-, quebraron un muro de suspicacias que separaba a los dos países.

El notable Tratado de Paz y Amistad firmado por los presidentes Alfonsín y Pinochet en 1984 sentó las bases para la posterior resolución ordenada de todos los diferendos fronterizos. También, se avanzó en una intensa y fructífera integración económica. El comercio bilateral creció velozmente y las inversiones directas chilenas se multiplicaron en la economía argentina.

Desafortunadamente, la exitosa política de integración energética fue desarticulada cuando el gobierno argentino priorizó el consumo interno y restringió las exportaciones. Desde entonces los excedentes de gas enviados a Chile han variado de acuerdo con las condiciones particulares del mercado interno argentino.

Se trata de un caso típico en que las urgencias internas impusieron su hegemonía sobre la política externa. Las restricciones pretendieron minimizar el impacto político interno de la escasez de gas natural.

La consiguiente carestía fue el resultado de las dificultades que encontró el gobierno argentino para proveerse de gas boliviano, de inesperadas modificaciones climáticas y de incrementos en el consumo interno. Asimismo, una errada política de control de precios del gas en boca de pozo, desalentó la exploración gasífera y redujo las reservas de gas en casi el $40 \%$ durante los últimos años.

Las modalidades adoptadas por la administración Kirchner para restringir las exportaciones de gas a Chile provocaron desconfianza en nuestro vecino. Las reacciones posteriores de la opinión pública, reabrieron, en ambos lados de la frontera, heridas históricas que parecían haber cicatrizado.

A posteriori, ambos gobiernos tomaron medidas concretas para normalizar la relación. La apertura del mercado interno aerocomercial argentino a la empresa chilena de bandera (LAN) es un gesto sin precedentes. Asimismo, la reciente ratificación por el parlamento argentino del acuerdo sobre el desarrollo minero conjunto en las áreas 
de frontera le permitirá a la empresa canadiense Barrick Gold avanzar en la concreción de un importante proyecto (Pascua Lama) cuyos beneficios recaen principalmente del lado chileno.

En los temas de defensa, la profundización de los vínculos entre las fuerzas armadas se inició durante la década de 1990. Chile forma parte desde 1998 de las fuerzas argentinas en la misión de las Naciones Unidas en Chipre. A fines del año 2006 se acordó la creación de una Fuerza Combinada (en proceso de organización) para la participación conjunta en Operaciones de Paz de las Naciones Unidas ${ }^{12}$.

Finalmente, en el Tratado de Maipú, suscripto a fines del año 2009 por los presidentes Bachelet y Kirchner, se crearon mecanismos de consulta permanente entre los dos países ${ }^{13}$. También se sentaron las bases para analizar con seriedad la construcción de nuevos pasos fronterizos operables durante todo el año ${ }^{14}$.

12 Battaglino, Jorge M., (2008) Transformaciones en la seguridad internacional en la post Guerra Fría: su impacto en América del Sur en: Estudios Internacionales, Universidad de Chile, No 160 mayo-agosto.

13 Tratado de Maipú de Integración y Cooperación entre la Republica Argentina y la República de Chile, 30 de octubre, 2009, www.casarosada.gov.ar

14 Los pasos actuales en la zona central y sur de la cordillera de los Andes se cierran a menudo durante el invierno. Los proyectos bajo consideración incluyen: en la provincia de Mendoza el Denominado Ferrocarril Trasandino Central (por Mendoza Capital) y el Paso de las Leñas (por San
En la actualidad, el postergado proyecto de ampliar la provisión de gas boliviano a la Argentina parecería finalmente encaminarse (ver próxima sección) y el gobierno, finalmente, ha puesto en marcha un sistema de incentivos que favorece la exploración de gas dentro del país. Quizás más adelante los gobiernos puedan negociar un nuevo acuerdo de integración energética de largo plazo, menos ambicioso pero más sólido que el anterior.

\section{El VECINDARIo}

Durante las últimas dos décadas, la Argentina ha concentrado toda su atención en la relación bilateral con Brasil y poco se ha hecho para desarrollar una integración intensa y fructífera con nuestro vecindario inmediato. $\mathrm{Me}$ refiero a Bolivia, Paraguay y Uruguay.

Brasil en cambio sí lo ha hecho, al menos en el campo económico, promoviendo sus empresas y productos en todos esos países. Es impensable soñar con vender exitosamente productos argentinos en las góndolas de Varsovia o Shanghai, si antes no lo hacemos en las de Asunción, Montevideo o La Paz.

Además, la integración regional será siempre incompleta y asimétrica si no profundizamos nuestra integración política, económica y cultural con nuestro vecindario inmediato.

La relación con Bolivia ha sido fructífera, aunque ha estado condicionada

Rafael) y; en la provincia de San Juan, el Paso de Agua Negra. 
por los profundos cambios políticos y sociales que están ocurriendo en dicho país.

Las enormes diferencias económicas y sociales de Bolivia están enraizadas en una gran heterogeneidad geográfica, cultural y étnica. El temor al conflicto civil violento y el riesgo de una fractura nacional están siempre latentes en la situación boliviana ${ }^{15}$. A la Argentina le conviene y le interesa una Bolivia unida, estable y próspera.

Si Bolivia se desestabiliza políticamente, la inmigración boliviana no va a ir ni a Brasil, ni a Chile, ni a Perú, sino que mayoritariamente vendrá a la Argentina, donde se estiman viven en la actualidad casi 300.000 bolivianos. Los servicios de salud, asistencia social y educación argentinos no están preparados para recibir un influjo repentino y masivo de inmigrantes de un país vecino.

La Argentina tiene además un interés estratégico en Bolivia como proveedora de gas natural. El desarrollo del gas boliviano estuvo históricamente acotado por el reducido tamaño de su mercado interno y por la falta de la infraestructura necesaria para exportar el gas, salvo al mercado interno argentino, aunque en cantidades limitadas.

La firma de un importante contrato de exportación con Brasil en 1996 abrió las puertas a un importante flujo de inversiones externas en exploración

15 Fernandez Saavedra, Gustavo (2008), Bolívia: una nova estrutura de poder, Política Externa, vol. 16 no. 3, Janeiro-Fevereiro. y producción. Las reservas probadas y probables, pasaron de aproximadamente 7 trillones de pies cúbicos en 1996 a casi 55 trillones en el año 2003. En la actualidad Brasil importa de Bolivia casi 30 millones de metros cúbicos diarios $^{16}$.

Bolivia vivió durante los últimos años un período de fuerte inestabilidad institucional. Su nuevo presidente, Evo Morales, nacionalizó el gas y el petróleo en el año 2006. La estatización del gas y precios más altos le permitieron equilibrar las finanzas públicas, incrementar el gasto social, impulsar el crecimiento económico (el más alto de la región durante el año 2009) y ser reelegido recientemente con una mayoría abrumadora.

Durante los últimos años, la Argentina importó un promedio de 5 millones de metros cúbicos diarios de gas. Un nuevo contrato de suministro de gas boliviano se firmó en el año 2006. El acuerdo suscripto prevé incrementar la importación a un promedio de 27,7 millones de metros cúbicos por día durante las próximas dos décadas.

Para poder satisfacer dicho contrato Bolivia deberá realizar importantes inversiones en capacidad de producción, transporte y compresión. En principio, un consorcio liderado por Repsol/YPF (incluye a Panamerican Energy y a British Gas) realizaría una parte sustancial de las inversiones privadas requeridas

16 Gall, Norman (2007), Gas en Bolivia: conflictos y contratos; Madrid, Real Instituto Elcano, 25 de enero. 
para perforar nuevos pozos y ampliar las plantas de procesamiento de gas.

Las inversiones están atrasadas. Se estima que el contrato será actualizado en el futuro inmediato en lo referido a plazos y volúmenes, así como a los compromisos que la Argentina deberá asumir respecto del transporte del gas (ampliando y utilizando primero la capacidad ociosa del Gasoducto Norte existente y construyendo luego la importante obra del Gasoducto Noreste).

Los acuerdos con Brasil y la Argentina le aseguran a Bolivia los dos mercados sudamericanos más importantes para exportar su gas durante las próximas décadas. La simultánea operación de estos contratos le facilitarán a Bolivia los medios económicos para impulsar su desarrollo, fortalecer sus instituciones e integrarse provechosamente en la región.

La relación con el Uruguay sufrió un notable deterioro durante los últimos tres años. La instalación y posterior puesta en marcha de una planta productora de celulosa en el territorio uruguayo, sobre la ribera compartida del río Uruguay, suscitó un lamentable problema entre los dos países.

El conflicto ocurre porque la operación de la planta podría contaminar el río compartido y afectar los intereses y el estilo de vida de la población ribereña del lado argentino.

La decisión uruguaya de poner en funcionamiento la planta celulósica y la decisión de los vecinos de la ciudad de Gualeguaychu de cerrar el puente en señal de protesta internacional han creado un espinoso conflicto.

Desafortunadamente, el Uruguay autorizó la construcción de la planta sin realizar los procedimientos de consulta previstos en el Tratado del Río Uruguay, firmado entre ambos países en 1975. Por su parte, el gobierno argentino debería haber participado activamente, y desde el inicio, en el proceso de evaluación ambiental, pero no lo hizo. Los gobiernos no han brillado en la gestión de este innecesario conflicto bilateral.

El impacto posterior del conflicto sobre la opinión pública en ambos países (producto de presiones políticas en cada uno de ellos) ha dañado una relación entre dos Estados independientes que son, en la historia y en los hechos, parte de una misma nación.

El embrollo genera, desde el punto de vista de la política exterior, dos importantes preocupaciones. Por un lado, en la Constitución Nacional la política exterior es atributo del gobierno federal y no de los gobiernos provinciales o municipales. El cierre del puente internacional por vecinos ha afectado dicho principio de autoridad.

Por otro lado, el conflicto afecta negativamente la reputación internacional de la Argentina. Un país que no es capaz de relacionarse eficazmente con aquellos países con quienes tiene mayor intimidad, ¿cómo lo hará con los demás? ¿En particular, con aquellos que tiene menos amistad histórica, contacto humano y geográfico? 
La decisión compartida por ambos gobiernos de elevar el desacuerdo a la Corte Internacional de Justicia de la Haya ha sido acertada. Permitió bajar el tono de la disputa y llevar la discusión a un terreno menos retórico.

Sería bueno que, después de conocida la decisión de la Corte Internacional de la Haya el gobierno argentino levante el bloqueo sobre el puente y que ambos países inicien negociaciones sobre una agenda de acciones concretas que resuelvan el problema.

\section{LA POLÍTICA COMERCIAL}

La política comercial internacional de los gobiernos Kirchner ha tenido un perfil activo ${ }^{17}$.

En el campo de las negociaciones multilaterales que se negocian en la llamada "Ronda Doha» bajo la égida de la Organización Mundial del Comercio- el gobierno argentino ha sostenido la tradicional posición argentina de que las reglas del comercio mundial deben ser modificadas para alcanzar un tratamiento más equitativo entre el comercio de productos agrícolas e industriales, así como lograr que países en desarrollo, como el nuestro, dispongan de mayor flexibilidad en la implementación de sus políticas de diversificación productiva.

Taiana, Jorge (2009), La inserción de argentina en un mundo en crisis, El Cronista Comercial, viernes 22 de mayo, Buenos Aires.
En el campo de la promoción comercial, el gobierno continuó los esfuerzos iniciados por los gobiernos anteriores para promover las exportaciones y los negocios del país en el exterior.

La Cancillería, con la colaboración de la Fundación Exportar, ha realizado numerosas misiones al exterior (incluyendo visitas presidenciales a China, la India, Medio Oriente y África del Norte) así como la apertura de nuevas embajadas en Asia Central (Armenia) y en África Subsahariana.

El gobierno promovió la exportación de bienes y servicios tecnológicamente avanzados, a través de su apoyo a las actividades internacionales de la Comisión Nacional de Energía Atómica, la de Actividades Espaciales y a diversas empresas con capacidades tecnológicas de avanzada en sectores diversos, como la energía nuclear, los satélites, la biotecnología, el software y la venta de equipos de producción de energía.

Respecto de los países emergentes (asiáticos, africanos, Medio Oriente y Europa oriental) los flujos comerciales han crecido rápidamente durante los últimos años. En particular con China (el intercambio bilateral total fue de US\$ 14.000 millones en el año 2008). La firma de un acuerdo estratégico entre los dos gobiernos (2004) y el reciente acuerdo de swap de monedas entre los bancos centrales (pesos versus yuanes, por el equivalente a US\$ 10.000 millones, vigente por tres años a partir de junio del 2009) merecen ser destacados.

La Argentina está comenzando a cosechar los resultados de una labor 
Felipe de la BAlze • La política exterior de los gobiernos Kirchner

sostenida por varios gobiernos durante las ultimas dos décadas.

En el marco del Mercosur, la Argentina negoció durante los últimos años varios acuerdos comerciales. El más significativo es el acuerdo automotriz con México. También se concretaron varios acuerdos de preferencias comerciales fijas-con la India, Israel, Jordania, Marruecos y la Unión Sudafricana.

\section{LAS FINANZAS INTERNACIONALES ${ }^{\text {I8 }}$}

Después del colapso del 2001-2003 la Argentina se transformó en un paria financiero internacional: perdió el acceso a los mercados de crédito, su calificación crediticia cayó a los niveles más bajos y su mercado local de capitales se contrajo y se desconectó del resto del mundo.

El gobierno Kirchner adoptó desde sus inicios un tono fuertemente crítico respecto de la responsabilidad del FMI en la crisis del 2001-2003. En consonancia con dicha posición, el gobierno ha sistemáticamente rechazado aceptar las revisiones que el FMI regularmente realiza respecto a las economías de sus países miembros.

Asimismo se adoptó una política de desendeudamiento y acumulación de reservas internacionales para reducir la dependencia financiera internacional del país.El gobierno tomó dos impor-

18 Ver además, comentarios complementarios en sección 1 (Estados Unidos) y sección 2 (Europa). tantes medidas para alcanzar dichos objetivos.

Por un lado, el sorpresivo repago de la totalidad de la deuda con el FMI por un monto de casi US\$ 10.000 millones a fines del año 2005. La cancelación, que tuvo un importante impacto político, se realizó utilizando las reservas excedentes del Banco Central.

Por otro lado, durante el año 2005, se reestructuró parcialmente la deuda impaga en los mercados de bonos internacionales. La guita obtenida sobre el valor nominal de la deuda y la reducción en la tasa de interés sobre los montos refinanciados, fueron significativas.

Aceptaron participar del canje US\$ 62.000 millones sobre un total de US\$ 81.000 millones de acreencias, lo que representó un $76 \%$ de aceptación. Sin embargo el monto de los bonos que no participaron del canje (por considerar la oferta argentina insatisfactoria), fue alto.

Los bonistas recalcitrantes iniciaron acciones legales contra el gobierno argentino que han resultado en juicios $\mathrm{y}$, en algunos casos, en embargos La consecuencia más gravosa fue el cierre indefinido de los mercados de capitales internacionales al crédito argentino.

El gobierno de Cristina Kirchner desea recuperar el acceso al crédito internacional. Para ello resolvió reabrir el canje durante los primeros meses del año 2010 a los tenedores de bonos que no aceptaron la propuesta anterior (aproximadamente US\$20.000 millones de bonos y US\$ 10.000 millones de intereses devengados impagos). 
Si la mayoría de los tenedores de bonos recalcitrantes aceptan la nueva propuesta y el gobierno regulariza la situación con el Club de París es factible que la Argentina pueda volver a colocar deuda en los mercados internacionales de capitales en un futuro no muy lejano ${ }^{19}$.

\section{Conclusiones}

Para poder evaluar las características y las consecuencias de la política exterior de los gobiernos Kirchner es necesario dejar de lado los rasgos invocados por el Gobierno y desentrañar la naturaleza real de la política externa instrumentada.

Toda política exterior es vulnerable a los efectos de una crisis interna de gran envergadura. La Argentina no fue una excepción a dicha regla.

Las repercusiones más gravosas de la crisis, respecto de la inserción internacional del país, fueron el quebranto de su crédito público y el profundo deterioro que ocurrió en la relación con las principales naciones europeas.

La política exterior de los últimos seis años no supo remediar estos dos severos reveses. Tampoco fue capaz de crear un clima de renovada confianza con los Estados Unidos, ni supo

19 El problema no es estrictamente financiero (las Agencias usualmente refinancian los montos adeudados a largo plazo) sino que gira alrededor del rechazo del gobierno argentino a la participación consultiva del FMI (otorgando la llamada «luz verde»), en el proceso de renegociación. articular con Brasil una política que destrabe el ya perenne estancamiento del Mercosur.

Pero las dificultades para administrar la herencia recibida no fueron los únicos sinsabores. Presionados por las urgencias de la política interna y por la inmediatez de la coyuntura, los gobiernos Kirchner operaron con una agenda internacional cambiante y un estilo de actuación a menudo reactivo y poco respetuoso de las formas diplomáticas usuales.

Los ingratos e innecesarios contratiempos que ocurrieron con Chile (por el gas) y con el Uruguay (por el conflicto ambiental) representan una penosa «marcha atrás» en el proceso de integración regional.

El estilo de conducción que el gobierno practica en la política interna, se proyectó al escenario internacional. El resultado fue un retraimiento en las relaciones internacionales de la Argentina con sus socios y vecinos. No hay que sorprenderse si la reputación del país en el exterior no se ha recuperado, si se han registrado pocas visitas oficiales durante los últimos años, si la mayoría de los embajadores extranjeros no tienen acceso a la cima del poder y si la influencia de la diplomacia profesional ha sido excesivamente baja en la determinación de muchas decisiones.

Seria provechoso para el país si durante los veinte meses que le quedan para finalizar su mandato el gobierno de la presidenta Cristina Kirchner avance constructivamente en la resolución de cuatro temas pendientes que 
la Argentina necesita remediar para normalizar su posición internacional.

Me refiero a (i) restablecer el crédito internacional argentino y (ii) normalizar la relación con Europa. Para ello , debe resolver el impasse con el Club de Paris, reestructurar la deuda impaga con la mayoría de los bonistas que quedaron fuera del canje del 2005 y avanzar, en la medida posible, en la resolución de los conflictos empresarios que se dirimen en los tribunales internacionales.

La firma de un acuerdo de cooperación y libre comercio entre el Mercosur y la Unión Europea sería el corolario simbólico que confirmaría ante el mundo el restablecimiento del crédito argentino y la normalización de la ajetreada relación con Europa.

Además, el gobierno podría (iii) regularizar la relación entre la Argentina y el Uruguay y restablecer una dosis de cordura en la relación bilateral. Para ello debe levantar el bloqueo vecinal al puente internacional y acordar con el gobierno de dicho país una política conjunta en materia de riesgos ambientales así como una agenda de integración bilateral concreta y amplia.

Finalmente (iv) contribuir a que se pongan en marcha las inversiones necesarias -en exploración, extracción y transporte- para hacer realidad el importante contrato de largo plazo que se firmó con Bolivia para asegurar la provisión de gas natural a la Argentina y darle realidad a la integración energética regional.
En materia de política exterior, el mundo respeta las continuidades y la previsibilidad y los países exitosos tienen gobiernos que aprovechan los aciertos de los anteriores ${ }^{20}$. Necesitamos dejar atrás la desafortunada costumbre de criticar irrestrictamente las acciones de los gobiernos anteriores -sin reconocer sus aciertos y juzgar sus decisiones, en el contexto en que fueron tomadas.

A la política exterior de los Kirchner no le ha faltado audacia en el pasado. Para que el aislamiento de los últimos años no quede como su principal legado, el gobierno debiera avanzar rápidamente en la normalización de las relaciones de nuestro país con el mundo. Quizás la historia -que es usualmente más generosa que los contemporáneosse lo reconozca.

Si así ocurriera, el gobierno que asuma en el 2011, hallará una plataforma más sólida para fortalecer los intereses argentinos en el mundo. Podremos así, poner en marcha una política exterior que refleje nuestro indiscutible potencial.

20 Cisneros, Andrés (2006), Políticas Exteriores de Estado, Archivos del Presente $\mathrm{N}^{\circ} 38$, Buenos Aires, mayo. 